\title{
O papel de imunoglobulinas na nefropatia da leptospirose em suínos ${ }^{1}$
}

\author{
Larissa M.F. Gonçalves ${ }^{2 *}$, Sônia M. Carvalho ${ }^{3}$, Ângela P. Campos ${ }^{4}$, Micherlene S. \\ Carneiro $^{4}$, Elis R.D.F.S. Silva ${ }^{4}$, Francisco A.L. Costa ${ }^{4}$ e Vanessa Castro ${ }^{5}$
}

\begin{abstract}
Gonçalves L.M.F., Carvalho S.M., Campos A.P., Carneiro M.S., Silva E.R.D.F.S., Costa F.A.L. \& Castro V. 2014. [The role of immunoglobulins in nephropathy of leptospirosis in pigs.] 0 papel de imunoglobulinas na nefropatia da leptospirose em suínos. Pesquisa Veterinária Brasileira 34(6):509-514. Setor de Patologia Animal, Universidade Federal do Piauí, Campus da Socopo s/n, Teresina, PI 64049-550, Brazil. E-mail: assiralm@gmail.com

Leptospirosis is an endemic worldwide anthropozoonosis, affecting humans and several species of domestic and wild animals. At the beginning of infection is the production of IgM to control the infection and after a few days, IgG is produced and cause lysis of circulating leptospires. The objective of this study was to identify deposits of immunoglobulins and antigens of leptospires in kidney tissue, to assess the role of immunoglobulins in the pathogenesis of leptospirosis nephropathy in pigs. We collected 139 blood samples and kidney of pigs from the cities of Timon/MA and Teresina/PI, to be evaluated by SAM, immunohistochemistry and PCR. Interstitial nephritis, fibrosis, vasculitis; swollen glomeruli hypercellularity and diffuse in a pig were main pathological changes found. Immunohistochemistry leptospira antigen detected in 60 pigs. Deposits of IgG, IgM and IgA were observed in the endothelium of glomerular capillaries, the capillaries intertubulares and the Bowman's capsule, marked focal, diffuse, global and segmental. The deposition of IgM and IgA was significantly higher in infected pigs, strangely deposits of IgG was significantly higher in non-infected pigs, where there was no presence of antigen leptospires nor tubulointerstitial injury. We conclude that Leptospira antigen in porcine kidney relates to deposits of IgM and IgA but not IgG deposits.
\end{abstract}

INDEX TERMS: Leptospirosis, immunoglobulins, swine.

RESUMO.- A leptospirose é uma antropozoonose endêmica em todo o mundo, que afeta o homem e várias espécies de animais domésticos e silvestres. No início da infecção há produção de IgM para o controle da infecção e após alguns dias, IgG são produzidas e provocam lise das leptospiras circulantes. Objetivou-se neste estudo identificar depósitos

\footnotetext{
${ }^{1}$ Recebido em 5 de fevereiro de 2014.

Aceito para publicação em 14 de abril de 2014.

${ }^{2}$ Departamento de Medicina Veterinária, Universidade Federal do Piauí (UFPI), Campus Professora Cinobelina Elvas, Bom Jesus, PI 64900-000, Brasil. *Autor para correspondência: assiralm@gmail.com

${ }^{3}$ Médica Veterinária da Unidade Regional, Agência Estadual de Defesa Agropecuária do Maranhão, Rua Celso Sereno 3, Centro, Presidente Dutra, MA 65760-000, Brasil.

${ }^{4}$ Departamento de Patologia Animal, UFPI, Campus da Socopo, Teresina, PI 64049-550, Brasil.

${ }^{5}$ Laboratório de Doenças Bacterianas da Reprodução, Instituto Biológico, Avenida Conselheiro Rodrigues Alves 1.252, São Paulo, SP 04014-002, Brasil.
}

de antígeno de leptospiras e imunoglobulinas no tecido renal, para avaliar o papel de imunoglobulinas na patogênese da nefropatia da leptospirose em suínos. Foram colhidas 139 amostras de sangue e rim de suínos das cidades de Teresina/PI e Timon/MA, que foram avaliadas pela SAM, imunoistoquímica e PCR. Nefrite intersticial, fibrose, vasculite, tumefação do tufo glomerular e hipercelularidade difusa foram as principais alterações histopatológicas encontradas. A imunoistoquímica detectou antígeno de leptospira em 60 suínos. Depósitos de IgG, IgM e IgA foram observados no endotélio de capilares glomerulares, dos capilares intertubulares e na cápsula de Bowman, com marcação focal, difusa, global e segmentar. A deposição de IgM e IgA foi significantemente maior nos suínos infectados. Estranhamente depósitos de IgG foi significantemente maior nos suínos não infectados, onde não havia presença de antígeno de leptospiras e nem lesão túbulo-intersticial. Concluímos que antígeno de leptospiras no rim de suínos está relacionado a depósitos de IgM e IgA mas não a depósitos de IgG. 
TERMOS DE INDEXAÇÃO: Leptospiroses, imunoglobulinas, suínos.

\section{INTRODUÇÃO}

As leptospiroses são antropozoonoses endêmicas em todo o mundo, causadas por espécies patogênicas de Leptospira sp. São consideradas doenças emergentes que afetam o homem e várias espécies de animais domésticos e silvestres (McBride et al. 2005).

O mecanismo de lesão provocado pelas leptospiras nos hospedeiros é complexo e pouco compreendido. Os estudos apontam para ação direta da bactéria sobre células do hospedeiro com produção de toxinas e enzimas proteolíticas e consequente lesão tecidual (Faine et al. 1999, Daher et al. 2010). Essa ação está relacionada à inibição da expressão de genes que codificam proteínas do citoesqueleto de células endoteliais e da matriz extracelular, proporcionando uma maior motilidade e disseminação das leptospiras no organismo (Martinez \& Fahey 2010).

Por outro lado, tanto o sistema imune inato (Daher et al. 2010) quanto o adquirido (Chassin et al. 2009), participam da defesa contra a ação das leptospiras sobre o organismo do hospedeiro. A lipoproteína LipL32 é a mais importante proteína de membrana externa (OMPs) que afeta diretamente as células dos túbulos proximais, aumentando consideravelmente a expressão de genes e de proteínas pró-inflamatórias, tais como óxido nítrico sintase induzível (iNOS), proteína 1 quimiotática para monócitos (CCL2/ MCP-1), RANTES (CCL5/Regulated on Activation, Normal $\mathrm{T}$ Cell Expressed and Secreted) e fator de necrose tumoral (TNF- $\alpha$ ). A estimulação de iNOS e CCL2-MCP-1 pelo LipL32, depende da presença de receptores Toll-like (TLRs) em células dos túbulos proximais, principalmente o TLR2 e TLR4 (Daher et al. 2010).

Por atuarem como patógenos extracelulares, as leptospiras incitam uma resposta imune adquirida dependente da produção de anticorpos e da ativação da via clássica do sistema do complemento, sendo que, a maioria dos anticorpos, são produzidos contra o LPS (lipopolissacarídeo). Estudos evidenciam que a fagocitose de leptospiras por neutrófilos e macrófagos só acontece após a opsonização por imunoglobulina G (IgG) específica (Banfi et al. 1982, Wang et al. 1984).

A resposta imune humoral é o principal mecanismo de defesa contra a leptospirose. No início da infecção são produzidas imunoglobulinas do tipo IgM para o controle da infecção. Após alguns dias, imunoglobulinas do tipo IgG são produzidas e provocam lise das leptospiras circulantes. Os anticorpos aderem ao lipopolissacarídeo da bactéria num processo de opsonização, preparando-os para serem fagocitados por macrófagos, o que resulta na diminuição dos sinais clínicos. No entanto, a bactéria permanece nos rins, sendo excretada na urina por vários meses após a infecção (Costa et al. 1981, Monteiro 2003). Nesse tipo de resposta imune, há uma maior participação de IgG e IgM, seja após infecção natural ou imunização, no entanto no homem observa-se uma maior produção de imunoglobulinas da classe IgM (Adler et al. 1980, Petchclai, Hiranda \&Potha 1991).

Complexos imunes circulantes podem estar correlacio- nados com a severidade dos sintomas. Sugere-se que o aumento na severidade da doença de Weil, possa ser resultante de uma resposta imune humoral intensa, já que falência renal, trombocitopenia e alterações pulmonares aparecem na fase imune da doença (Galli et al. 1985, Abdulkader et al. 2002). Em um estudo experimental realizado com cobaias, foi observado grande quantidade de antígeno de leptospira, na fase tardia da infecção, localizado principalmente no interstício renal, enquanto os depósitos de imunoglobulinas G (IgG) e complemento 3 (C3) foram visualizados em glomérulos e nas paredes de pequenos vasos sanguíneos (Yasuda et al. 1986), sugerindo que as lesões renais observadas na leptospirose possam ser mediadas por complexo imune (Noronha et al. 1995).

0 presente estudo teve como objetivo identificar depósitos de antígeno de leptospiras e imunoglobulinas no tecido renal, para avaliar o papel de imunoglobulinas na patogênese da nefropatia da leptospirose em suínos.

\section{MATERIAL E MÉTODOS}

O material constou de amostras de sangue e fragmentos de rim de 139 suínos adultos, provenientes das cidades de Teresina/PI e Timon/MA.

Amostras de sangue foram colhidas no momento da sangria do animal e o soro foi armazenado a $-20^{\circ} \mathrm{C}$ até o processamento. Após o abate dos animais, foram colhidos fragmentos de rim, fixados em formol neutro a $10 \%$ tamponado com fosfato $0,01 \mathrm{M}$ pH 7,2 (formol tamponado), em solução de Duboscq-Brasil e conservados em meio RPMI (Roswell Park Memorial Institute) com glicerol a $10 \%$.

A detecção de anticorpos anti-leptospiras foi realizada pela técnica de Soroaglutinação Microscópica (SAM) em laboratórios credenciados. 0 critério adotado para o soro ser considerado como reagente foi de $50 \%$ de Leptospiras aglutinadas por campo microscópico em aumento de 100 vezes. 0 sorovar registrado foi aquele que apresentou maior título, sendo as demais aglutinações consideradas reações cruzadas.

Para o estudo das alterações histopatológicas foram utilizados fragmentos de rins, de 15 suínos infectados e de seis suínos não infectados nos testes de SAM, imunoistoquímica (IMH) e Reação em Cadeia pela Polimerase (PCR). 0 material foi processado em histotécnico, posteriormente incluídos em parafina e cortados em micrótomo com 4-5 $\mu \mathrm{m}$ de espessura. Os cortes foram montados em lâminas e corados com Hematoxilina-Eosina (H-E), ácido periódico de Schiff (PAS), tricrômico de Masson (Masson), ácido periódico prata metanamine (PAMS) e imunoperoxidade indireta.

Cortes de tecido renal foram preparados em lâminas com adesino Silane A174 (Pharmacia, USA) para imunoistoquímica. Após desparafinização procedeu-se o bloqueio de peroxidase endógena, seguido do desmascaramento de antígeno em forno microondas em solução Tris $\mathrm{HCl}$ pH 1 . Em seguida as amostras foram incubadas com anticorpo policlonal de coelho anti-leptospira (produzido no Setor de Patologia Animal da Universidade Federal do Piauí - UFPI) e com anticorpo monoclonal anti-IgM (NB716), anti-IgG (NB738) e anti-IgA (NB725) de suíno (NOVUS BIOLOGICALS, LLC). A amplificação da reação foi feita com o sistema "EnVision+", peroxidase (Dako Corporation, Carpinteria, CA, USA, K4003), para detecção de antígeno de leptospira e com o sistema Estreptavidina-peroxidase (Dako Corporation, Carpinteria, CA, USA, Código P0397), para detecção das imunoglobulinas. A revelação das reações foi feita com solução de Diaminobenzidine/ Plus, líquido, K047 (Diagnostic BioSystems, USA) e contracoloração com hematoxilina de Harrys (QEEL, SP). 
Os parâmetros utilizados para definir a marcação de imunoistoquímica, tanto para antígeno de leptospira, quanto para depósitos de imunoglobulinas, foram a intensidade da coloração, identificação do tipo de célula imunocorada, distribuição e localização das células e depósitos imunocoradas, sendo que uma coloração leve foi considerada negativa.

Do tecido renal congelado foi feita a extração e purificação de DNA utilizando-se o Wizard ${ }^{\circledR}$ Genomic DNA Purification Kit (Promega), seguindo instruções do fabricante.

Para amplificação do DNA de Leptospira spp. foram utilizados os oligonucleotídeos Lep-1 (5' GGCGGCGCGTCTTAAACATG 3') e Lep-2 (5’ TTCCCCCCATTGAGCAAGATT 3') (Mérien et al. 1992) (Invitrogen ${ }^{\circledR}$ ). 0 ciclo empregado foi o preconizado por Richtzenhain (Richtzenhain et al 2002).

0 produto amplificado (331 pb para o gene 16S RNAr de Leptospira sp.) foi submetido a eletroforese em gel de agarose a 1,5\% e corado com brometo de etídio, utilizando-se tampão de corrida TBE 10 X (0,9 M Tris, 0,9 M ácido bórico e 0,02 M EDTA). Para visualização das bandas foi utilizado um transluminador ultravioleta (300-320nm) e fotografado em sistema de fotodocumentação MiniBIS Pro (DNR Bio-imaging Systems Ltd, Jerusalem, Israel) do Setor de Patologia Animal da UFPI.

Como controle positivo para a leptospirose foi utilizado DNA extraído de cultura de Leptospira interrogans sorovar Icterohaemorragiae. Como controle negativo da PCR foi utilizado a mistura dos reagentes usados na reação da PCR sem DNA molde, completando-se o volume com $5 \mu \mathrm{L}$ de água ultrapura. Para controle interno da reação foi utilizado a mistura dos reagentes usados na reação, porém com os primers para $\beta$-actina.

A análise dos dados foi realizada por testes estatísticos não paramétricos: Método de Kruskal-Wallis e Student-Newman-Keuls, para comparação entre grupos e o teste de Mann-Whitney, para comparação entre dois grupos. Adotou-se o nível de significância de $\mathrm{p}<0,05$.

\section{RESULTADOS}

Das 139 amostras de soro analisadas pela prova de SAM, oito $(5,7 \%)$ foram reagentes para os sorovares: Grippotyphosa, Hardjo, Canícola, Pyrogenes e Icterohaemorrhagiae.

As alterações túbulo-intersticiais encontradas foram nefrite intersticial, caracterizada pela presença predominante de linfócitos e macrófagos (Fig.1), de distribuição focal, peritubular e perivascular, com intensidade variando de mínima a moderada. Observou-se também fibrose de intensidade mínima a média, vasculite, tumefação de endotélio vascular, degeneração de células epiteliais tubulares, atrofia de túbulos, congestão da região medular, tumefação do tufo glomerular e hipercelularidade difusa em um suíno. Nos suínos não infectados, tais alterações não foram observadas.

A técnica de imunoperoxidase demonstrou antígeno de leptospira em 60 suínos dos 139 analisados. A avaliação semi-quantitativa realizada em 23 suínos, revelou que o antígeno estava presente em maior quantidade nas células epiteliais tubulares, seguido pelas células glomerulares, células intersticiais, células epiteliais parietais da cápsula de Bowman e células inflamatórias (Fig.2) ( $\mathrm{p}<0,05$; Teste de Kruscal-Wallis).

Depósitos de IgG, em um padrão granular, foram observados no endotélio de capilares glomerulares, como marcação focal, global e segmentar, na cápsula de Bowman, no endotélio dos capilares intertubulares (Fig.3). IgM foi observada no endotélio de capilares glomerulares, em

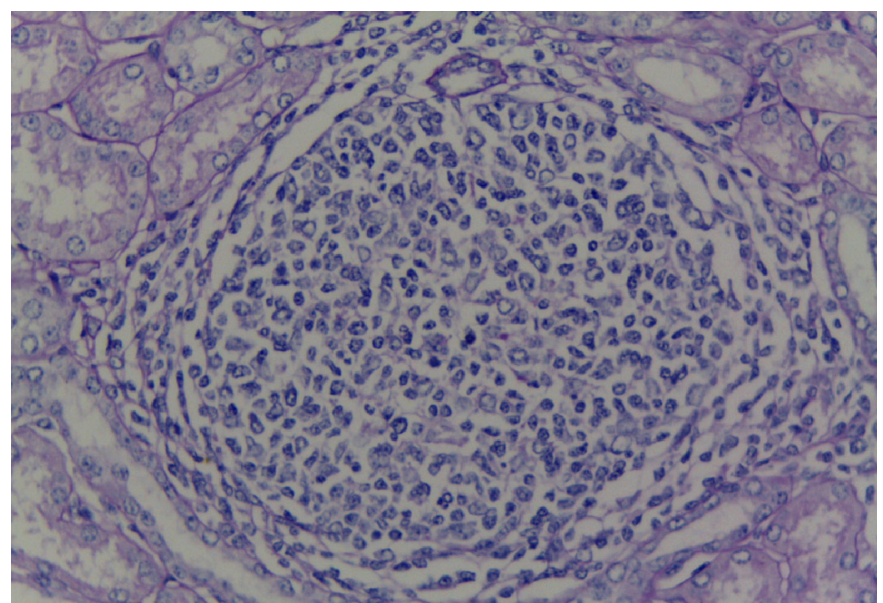

Fig.1. Rim. Suíno infectado naturalmente por Leptospira spp.. Infiltrado inflamatório mononuclear na região cortical. PAS, obj.40x.

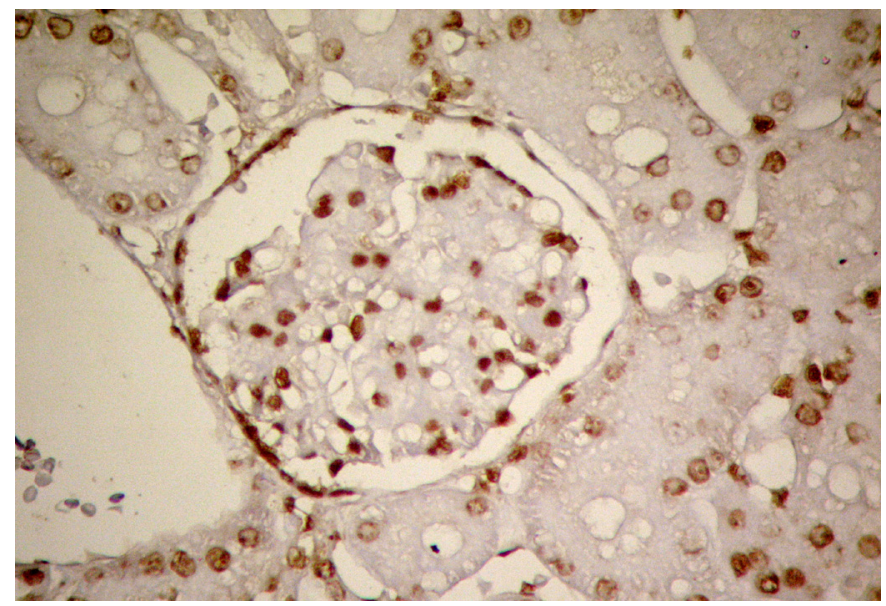

Fig.2. Antígeno de Leptospira em células glomerulares, células epiteliais tubulares e células epiteliais parietais da cápsula de Bowman, em rim de suíno naturalmente infectado por Leptospira sp. Imunoperoxidase. Obj.40x.

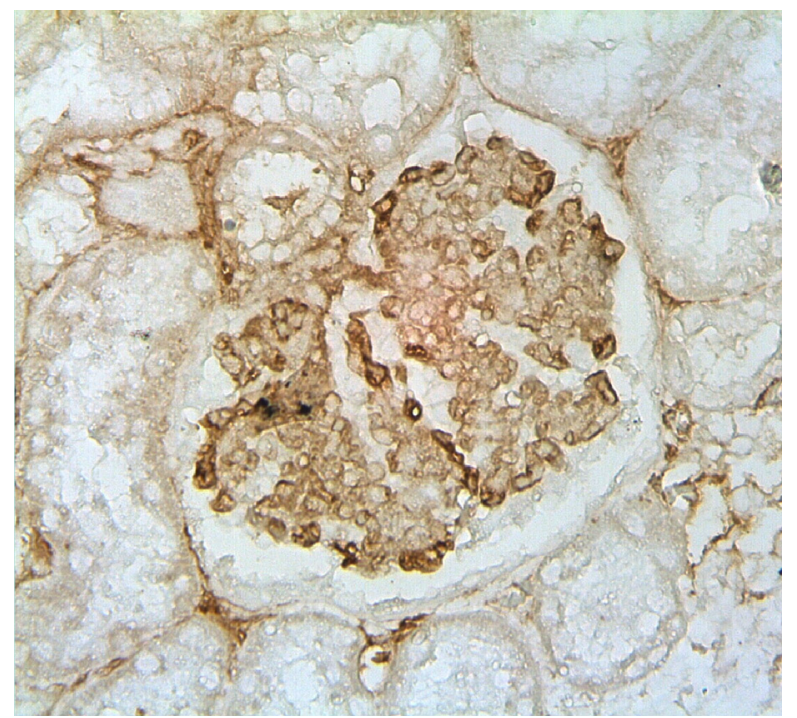

Fig.3. IgG no glomérulo de suíno naturalmente infectado por Leptospira spp. Imunoperoxidase, obj.40x 
um padrão granular, apresentando uma marcação difusa e global, e no endotélio dos capilares intertubulares (Fig.4). A imunocoloração para IgA foi observada no endotélio de capilares glomerulares, em um padrão granular, com marcação focal, global e segmentar; na cápsula de Bowman, no endotélio dos capilares intertubulares e em células epiteliais tubulares (Fig.5).

IgM e IgA em glomérulo estavam presentes em quantidade maior nos suínos infectados em comparação aos não infectados, sendo que para IgM, houve diferença significante também em capilares intertubulares (Fig. 6 e 7) ( $p<0,05$; Teste Mann Whitney), no entanto, a marcação de IgG em glomérulo nos suínos não infectados foi maior que nos infectados (Fig.8) ( $\mathrm{p}<0,05$; Teste Mann Whitney).

A técnica de PCR mostrou amplificação de DNA de leptospiras em sete (5\%) das 139 amostras de tecido renal analisadas.

O diagnóstico de leptospirose é complexo, pois dos três métodos utilizados apenas a IMH detectou antígeno onde a sorologia também detectou infecção, mas a recíproca não é verdadeira, pois foram detectados antígenos de leptospiras por IMH onde não foi encontrado sorovar infectante, e a sorologia e IMH detectaram infecção onde a PCR não de-

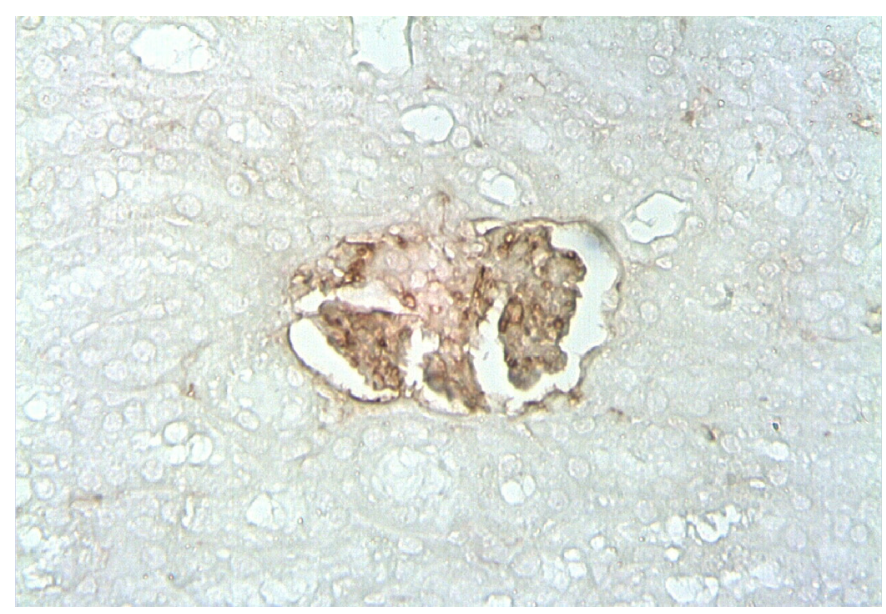

Fig.4. IgM no glomérulo de suíno naturalmente infectado por Leptospira spp. Imunoperoxidase, obj.40x.

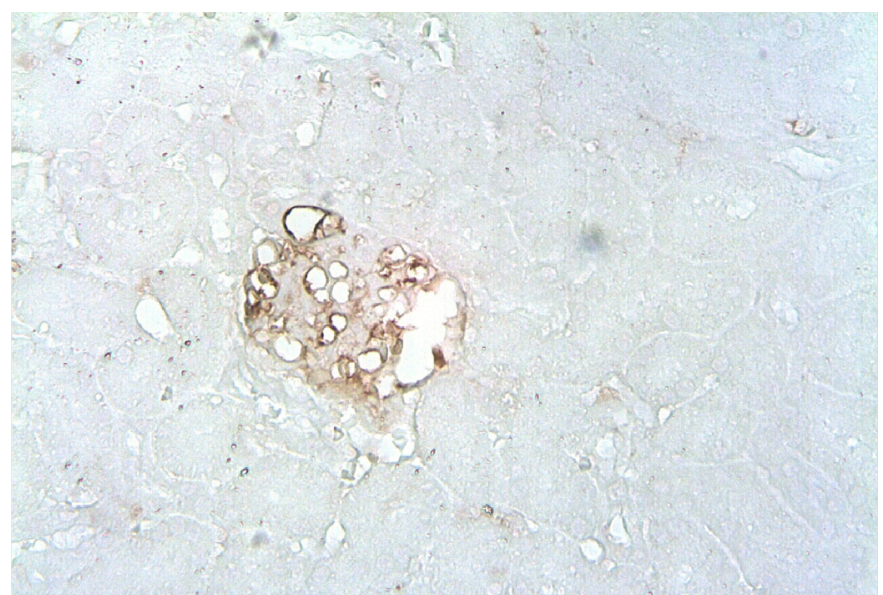

Fig.5. IgA no glomérulo de suíno naturalmente infectado por Leptospira spp. Imunoperoxidase, obj.40x.

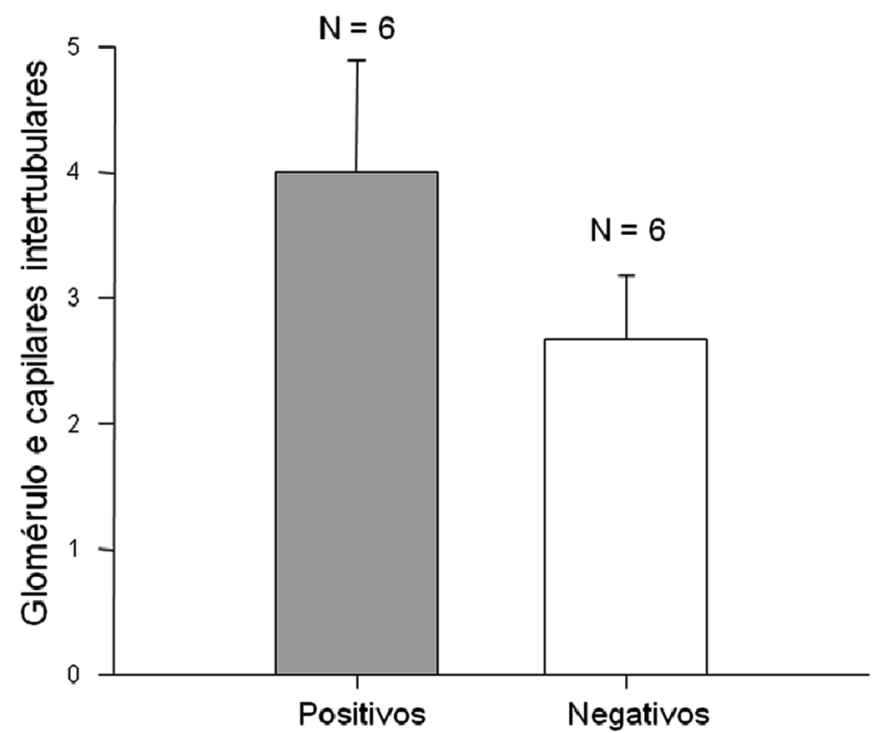

Fig.6. Análise semiquantitativa da marcação de IgM (mediana de escores e intervalo entre percentis 25 e 75) em suínos infectados e não infectados. $\mathrm{N}=\mathrm{N}$ o de animais por grupo. ${ }^{*} \mathrm{p}<0,05$ (Teste de Mann Whitney).

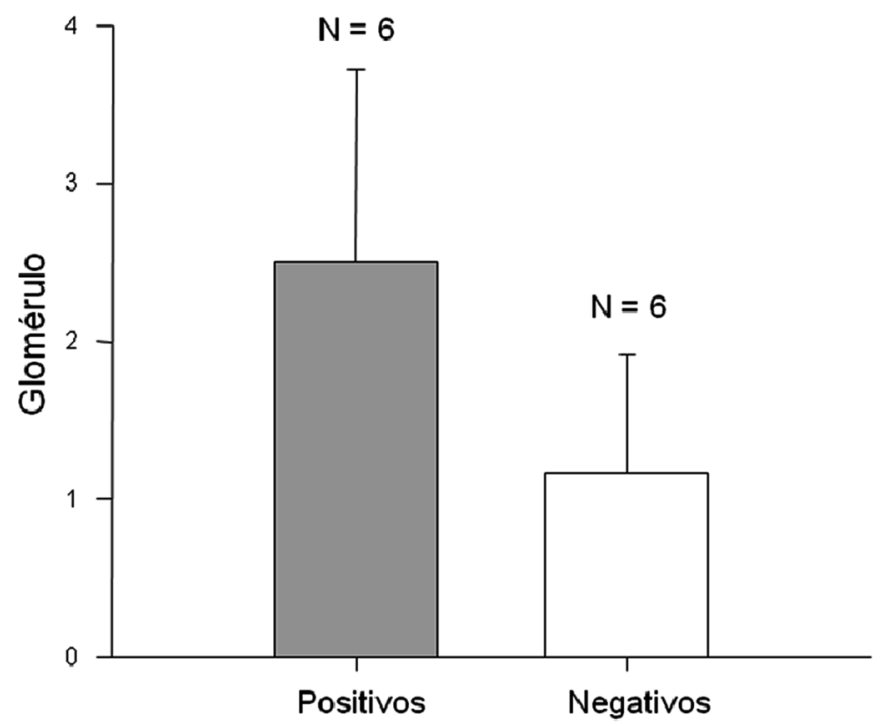

Fig.7. Análise semiquantitativa da marcação de IgA (mediana de escores e intervalo entre percentis 25 e 75) em suínos infectados e não infectados. $\mathrm{N}=\mathrm{N} N$ de animais por grupo. ${ }^{*} \mathrm{p}<0,05$ (Teste de Mann Whitney).

tectou (Quadro1). A comparação dos três testes utilizados para o diagnóstico de infecção por leptospiras, revelou que a imunoistoquímica apresentou sensibilidade de 53,6\% e $53,1 \%$ comparada à sorologia (SAM) e reação em cadeia pela polimerase (PCR), respectivamente, e especificidade de $100 \%$.

\section{DISCUSSÃO}

As principais alterações histopatológicas encontradas nos suínos infectados foram nefrite intersticial linfohistiocitária, focal, peritubular e perivascular, fibrose, vasculite, tumefação de endotélio vascular, degeneração de células 


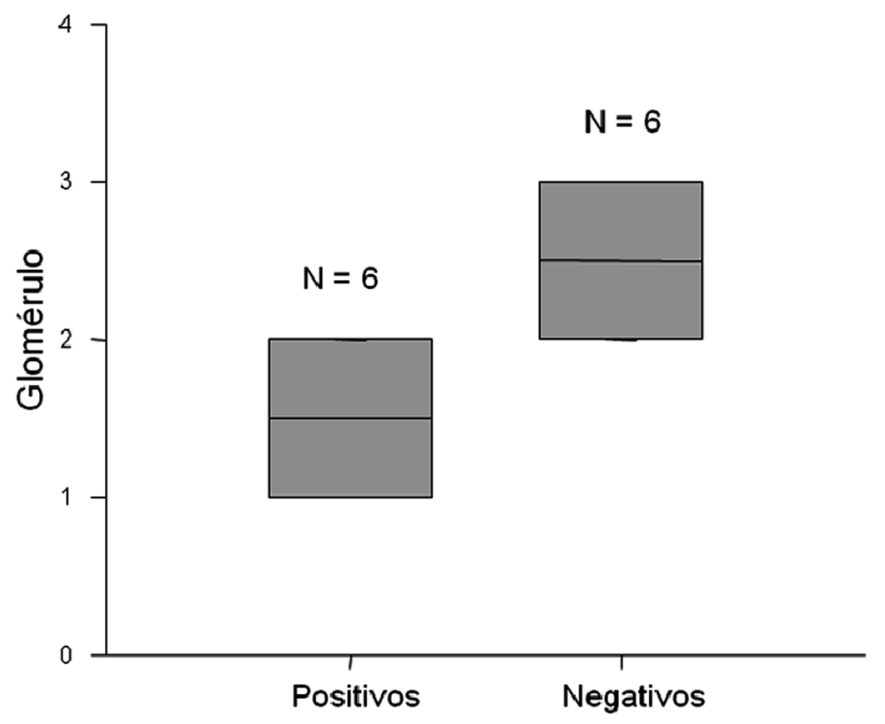

Fig.8. Análise semiquantitativa da marcação de IgG (mediana de escores e intervalo entre percentis 25 e 75) em suínos infectados e não infectados. $\mathrm{N}=\mathrm{N}$ o de animais por grupo. ${ }^{*} \mathrm{p}<0,05$ (Teste de Mann Whitney).

Quadro 1. Resultados da sorologia, da análise semiquantitativa de antígeno de Leptospira spp., IgG, IgM e de IgA, por imunoperoxidase, em rim de suínos naturalmente infectados. Imunoperoxidase

\begin{tabular}{cccccccc}
\hline Animais & SAM & Sorovar & IMH & IgG & IgM & IgA & PCR \\
\hline Infectados & & & & & & & \\
02 & - & - & - & + & $4^{\mathrm{a}}$ & $1^{\mathrm{a}}$ & + \\
06 & - & - & - & $2^{\mathrm{b}}$ & + & $3^{\mathrm{a}}$ & + \\
53 & - & - & - & $2^{\mathrm{b}}$ & + & $5^{\mathrm{a}}$ & + \\
80 & - & - & + & $1^{\mathrm{b}}$ & + & + & + \\
87 & - & - & + & + & + & + & + \\
89 & - & - & + & + & + & + & + \\
110 & - & - & - & $1^{\mathrm{b}}$ & $5^{\mathrm{a}}$ & $3^{\mathrm{a}}$ & + \\
111 & + & Icterohaemorragiae & + & + & $3^{\mathrm{a}}$ & + & - \\
115 & + & Grippotyphosa & + & + & + & + & - \\
121 & + & Grippotyphosa & + & + & + & $3 \mathrm{a}$ & - \\
123 & + & Grippotyphosa & + & + & $4^{\mathrm{a}}$ & + & - \\
131 & - & - & + & + & $5^{\mathrm{a}}$ & + & - \\
138 & - & - & + & $2^{\mathrm{b}}$ & + & + & - \\
142 & + & Pyrogenes & + & $1^{\mathrm{b}}$ & $3^{\mathrm{a}}$ & $1^{\mathrm{a}}$ & - \\
143 & + & Canícola & + & + & + & + & - \\
Não infectados & & & & & & \\
03 & - & - & - & $2^{\mathrm{a}}$ & $2^{\mathrm{b}}$ & $0^{\mathrm{b}}$ & - \\
17 & - & - & - & $3^{\mathrm{a}}$ & $3^{\mathrm{b}}$ & $2^{\mathrm{b}}$ & - \\
42 & - & - & - & $2^{\mathrm{a}}$ & $2^{\mathrm{b}}$ & $1^{\mathrm{b}}$ & - \\
56 & - & - & - & $3^{\mathrm{a}}$ & $3^{\mathrm{b}}$ & $1^{\mathrm{b}}$ & - \\
98 & - & - & - & $2^{\mathrm{a}}$ & $3^{\mathrm{b}}$ & $2^{\mathrm{b}}$ & - \\
116 & - & - & - & $3^{\mathrm{a}}$ & $3^{\mathrm{b}}$ & $1^{\mathrm{b}}$ & - \\
\hline
\end{tabular}

Letras diferentes na mesma coluna indicam diferença significante. ${ }^{*} \mathrm{p}<0,05$. Teste de Mann Whitney.

epiteliais tubulares, atrofia de túbulos, tumefação do tufo glomerular e hipercelularidade glomerular difusa em um suíno. Essas alterações variavam em intensidade mínima a moderada. Nally et al. 2004 verificaram pouco infiltrado inflamatório peritubular, sendo que os achados mais freqüentes foram necrose de células tubulares, com algumas apoptóticas, e aumento de mitoses, como indicativo de regeneração tubular, sem alteração glomerular. Em ca- mundongos infectados, Marinho 2008 verificou hipercelularidade glomerular, infiltrado mononuclear focal, perivascular e periglomerular, espessamento de membrana basal glomerular e degeneração de túbulos da cortical. A lesão túbulo intersticial encontrada nos suínos deste estudo e também relatada, por Maxie (1993), é a lesão típica provocada pelas leptospiras, à exceção da lesão glomerular que não tem sido descrita com muita frequência (Marinho 2008, Gonçalves et al. 2011).

As causas das alterações renais observadas ainda não são bem conhecidas, mas estão relacionadas com a presença de antígeno de leptospira, que estava localizado em células epiteliais tubulares, células glomerulares, células intersticiais, cápsula de Bowman e em menor quantidade nas células do infiltrado inflamatório. Não foi encontrada a bactéria nos rins, mas antígeno e DNA de leptospiras foram detectados. Em modelos experimentais de cobaias e Hamster as leptospiras tem sido observadas na membrana basal glomerular, entre as células tubulares, no lúmen de túbulos, no interstício e, em alguns casos, dentro de glomérulos (Haawinckel et al. 2004, Nally et al. 2004).

Depósitos de imunoglobulinas em glomérulos, podem ser decorrentes da formação de complexo imune circulante (Noronha et al. 1995), ou de uma reação cruzada com proteínas da membrana basal glomerular em casos de glomerulonefrite anti-membrana basal glomerular, como tem sido observado no homem (Craig et al. 2009). 0 primeiro caso parece improvável, pois, apesar de alguns estudos apontarem para esse mecanismo (Noronha et al. 1995), sabe-se que a sobrevivência de leptospiras nos rins decorre da falta de ativação do sistema complemento (Meri et al. 2005) e essa ausência do complemento não favorece a formação de complexo imune. No segundo caso, mais provável, ainda não conhecemos a ação de anticorpos anti-membrana basal glomerular nos animais, à exceção do cão em casos de nefropatia hereditária (Thorner et al. 1989), de modo que esse aspecto não pode ser esclarecido neste trabalho. Por outro lado, depósitos de IgM, IgA, IgG e C3 tem sido observados no alvéolo pulmonar do homem e em cobaias infectadas experimentalmente com leptospiras, como parte da síndrome de Goodpasture (Craig et al. 2009), sugerindo que esse mesmo processo possa ocorrer também nos rins (Nally et al. 2004, Croda et al. 2010).

De um modo em geral depósitos de imunoglobulinas estavam presentes tanto nos suínos infectados quanto nos não infectados. Fraga et al. 2011 destacaram que ainda não está claro se depósitos de imunoglobulinas nos rins podem estar relacionados com a lesão renal. Contudo, a deposição de IgM e IgA foi significantemente maior nos suínos infectados, onde antígeno de leptospiras e lesão túbulo-intersticial estavam presentes, comparado aos não infectados, o que aponta para a importância dessas imunoglobulinas na patogênese da lesão renal. Estranhamente depósitos de IgG foram significantemente maiores nos suínos não infectados, onde não havia presença de antígeno de leptospiras e nem lesão túbulo-intersticial, sugerindo um mecanismo de proteção e não de injúria renal, pois na ausência e baixa expressão de IgG, antígeno de leptospiras estavam presentes. 


\section{CONCLUSÃO}

Concluímos que antígeno de leptospiras no rim de suínos está relacionado a depósitos de IgM e IgA mas não a depósitos de IgG.

Agradecimentos.- Ao Laboratório de Doenças Bacterianas da Reprodução do Instituto Biológico de São Paulo; ao Laboratório de Zoonoses do Departamento de Medicina Veterinária Preventiva da Escola de Veterinária da Universidade Federal de Minas Gerais; ao Programa de Pós-Graduação em Ciência Animal e Setor de Patologia Animal da Universidade Federal do Piauí do Centro de Ciências Agrárias. Coordenação de Aperfeiçoamento de Pessoal de Nível Superior (CAPES).

\section{REFERÊNCIAS}

Abdulkader R.C., Daher E.F., Camargo E.D., Spinosa C. \& da Silva M.V. 2002. Leptospirosis severity may be associated with the intensity of humoral immune response. Revta Inst. Med. Trop. São Paulo 44:79-83.

Adler B., Murphy K.H., Locarnini S.A. \& Faine S. 1980. Detection of specific anti-leptospiral immunoglobulin $\mathrm{M}$ and immunoglobulin $\mathrm{G}$ in human serum by solid phase enzyme-linked immunosorbent assay. J. Clin. Microbiol. 11:452-457.

Banfi E., Cinco M., Bellini M. \& Soranzo M.R. 1982. The role of antibodies and serum complement in the interaction between macrophages and leptospires. J. Gen. Microbiol. 28:813-816.

Chassin C., Picardeau M., Goujon J.M., Bourhy P., Quellard N., Darche S., Badell E., d'Andon M.F., Winter N., Lacroix-Lamande S., Buzoni-Gatel D., Vandewalle A. \& Wert C. 2009. TLR4- and TLR2-mediated B cell responses control the clearance of the bacterial pathogen, Leptospira interrogans. J. Immunol. 183:2669-2677.

Costa A.V., Silvio I.C., Miranda-Filho G., Silva V.V., Caldas E.M., Brito E. \& Sampaio M.B. 1981. Estado imunológico na leptospirose. Revta Inst. Adolfo Lutz, São Paulo, 41:93-100.

Craig S.B., Graham G.C., Burns M.A., Dohnt M.F., Wilson R.J., Smythe L.D., Jansen C.C. \& McKay D.B. 2009. Leptospirosis and Goodpasture's syndrome: testing the aetiological hypothesis. Ann. Trop. Med. Parasitol. 103:647-651.

Croda J., Neto A.D., Brasil R.A., Pagliari C., Nicodemo A.C. \& Duarte M.I.S. 2010. Leptospirosis pulmonary haemorrhage syndrome is associated with linear deposition of immunoglobulin and complement on the alveolar surface. Clin. Microbiol. Infection 16:6.

Daher E.F., de Abreu K.L.S. \& Silva Junior G.B. 2010. Leptospirosis-associated acute kidney injury. J. Bras. Nefrol. 32:400-407.

Faine S., Alder B., Bolin C. \&Perolat P. 1999. Leptospira and Leptospirosis. $2^{\text {nd }}$ ed. MediSci, Melbourne. 272p.

Fraga T.R., Barbosa A.S. \& Isaac L. 2011. Leptospirosis: aspects of innate immunity, immunopathogenesis and immune evasion from the complement system. Scand. J. Immunol. 73:408-419.

Galli M., Esposito R., Crocchiolo P., Chermotti M., Gasparro P. \& Dall'Agio P.1985 . Immune complexes in leptospirosis. Infection 13:156.
Gonçalves L.M.F., Mineiro A.L.B.B., Carvalho S.M., Campos Â.P., Melo Evangelista L.S., Pinho F.A., Moreira É.C. \& Costa F.A.L. 2011. Pesquisa de aglutininas, antígeno de leptospiras e apoptose em rim de suínos naturalmente infectados por Leptospira sp. Pesq. Vet. Bras. 31:561-568.

Haanwinckel M.C.S., Megid J. \& Souza L.C. 2004. Avaliação da prova de imunoperoxidase como recurso diagnóstico na leptospirose animal. Arqs Inst. Biológico, São Paulo, 71:293-301.

Marinho M. 2008. Leptospirose: fatores epidemiológicos, fisiopatológicos e imunopatogênicos. Vet.. Zootec. 15:428-434.

Martinez-Lopez D.G., Fahey M. \& Coburn J. 2010. Responses of human endothelial cells to pathogenic and non-pathogenic leptospira species. PLoS. Negl. Trop. Dis. 4:918.

Maxie M.G. 1993. The urinary system, p.447-538. In: Jubb K.V.F., Kennedy P.C. \& Palmer N. (Eds), Pathology of Domestic Animals. $4^{\text {th }}$ ed. Academic Press, London.

McBride A.J., Athanazio D.A., Reis M.G. \& Ko A.I. 2005. Leptospirosis. Curr. Opinion Infect. Dis. 18:376-386.

Meri T., Murgia R., Stefanel P., Meri S. \& Cinco M. 2005. Regulation of complement activation at the C3-level by serum resistant leptospires. Microb. Pathog. 39:139-47.

Mérien F., Amouriaux P., Perolat P., Baranton G. \& Saint-Girons I. 1992. Polymerase chain reaction for detection of Leptospira spp. in clinical samples. J. Clin. Microbiol. 30:2219-2224.

Monteiro G.R.G. 2003. Efetividade da doxiciclina na profilaxia contra leptospirose. Dissertação de Mestrado, Universidade Federal do Rio Grande do Norte, Natal, RN. 68p.

Nally J.E., Chantranuwat C., Wu X.Y., Fishbein M.C., Pereira M.M., Silva J.J.P., Blanco D.R. \& Lovett M.A. 2004. Alveolar septal deposition of immunoglobulin and complement parallels pulmonary hemorrhage in a guinea pig model of severe pulmonary leptospirosis. Am. J. Pathol. 163:11151127.

Noronha I.L., Waldherr R., Rambausek M. \& Ritz E. 1995. Nefropatia mesangial primária da IgA: aspectos clínicos e imunopatológicos. J. Bras. Nefrol. 17:21-29.

Petchclai B., Hiranda S.S. \& Potha U. 1991. Gold immunoblot analysis of IgM-specific antibody in the diagnosis of human leptospirosis. Am. J. Trop. Med. Hyg. 45:672-675.

Richtzenhain L.J., Cortez A., Heinemann M.B., Soares R.M., Sakamoto S.M., Vasconcellos S.A., Higa Z.M., Scarcelli E. \& Genovez M.E. 2002. A multiplex PCR for the detection of Brucella spp. And Leptospira spp. DNA from aborted bovine fetuses. Vet. Microbiol. 87:139-147.

Thorner P., Baumal R., Valli V.E., Mahuran D., McInnes R. \& Marrano P. 1989. Abnormalities in the NC 1 domain of collagen type IV in GBM in canine hereditary nephritis. Kidney International 35:843-850.

Wang B., Sullivan J.A., Sullivan G.W. \& Mandell G.L. 1984. Role of specific antibody in interaction of leptospires with human monocytes and monocyte-derived macrophages. Infect. Immun. 46:809-813.

Yasuda P.H., Hoshino-Shimizu S., Yamashiro E.H. \& De Brito T. 1986. Experimental Leptospirosis (L. Interrogans Serovar Icterohaemorrhagiae) oh the detection in the kidney. Exp. Pathol. 29:35-43. 